\title{
CORRESPONDENCE
}

\section{MECHANISM OF LOCOMOTION OBSERVED ON CATERPILLAR HAIRS}

To the Editorial Committee of the British Journal of OPHTHALMology.

SIRS-Although ophthalmia nodosa has been known for more than a century (Schön, 1861), the mechanism of the migration of caterpillar hairs has remained controversial. There is no need to enumerate the explanations proposed, but one point should be noted here which has rarely been mentioned in the recent literature, not even in the excellent paper by Watson and Sevel (1966).

Pathologically, it has long been known that caterpillar hairs entering the conjunctiva or cornea become surrounded by a granulation nodule consisting of giant cells, epithelioids, and lymphocytes; these infiltrates develop at the broken-off end of the hair from which a toxic substance leaks into the surrounding tissue. The undamaged tip of the hair is not surrounded by these granulations unless, for some reason, the hair remains in the tissue for a longer period of time. While the soft conjunctival and episcleral tissues permit the formation of a protruding nodule, the stiffer cornea and sclera do not expand; this mechanical difference together with the shape of the broken-off hair led to the conclusion (Ascher, 1937) that the cellular infiltrate pressing against the broken-off end of the hair pushes it forward in the direction of least resistance, i.e. with the sharp unbroken tip forwards and in the same interlamellar space unless the sharp tip happens to enter a neighbouring interlamellar space; then, the hair will continue to be pushed forwards parallel to the fibres of this lamella. Some authors have assumed that barbs might prevent the hair from wandering with the undamaged tip forwards, but a convincing experiment was performed by Geserick (1954): under the corneal microscope he used a keratome to divide a caterpillar hair imbedded in the cornea; the proximal end of the hair remained immobile, surrounded by an infiltrate of oval shape while the distal sharp end continued to migrate forwards, being apparently pushed in that direction by a triangular exudate at its cut-off end. This experiment has confirmed the explanation given 30 years ago and has refuted the assumption that the barbs would interfere with the movement of the hair in the direction of its natural tip. Yours faithfully,

KARL W. ASCHER.

1404 East McMillan Street,

Cincinnati, OHIO, 45206, U.S.A.

November 4, 1967.

Ascher, K. (1937). Med. Klin., 33, 297.

\section{REFERENCES}

GeSERICK, H. (1954). Z Zl. Chir., 79, 764.

SchöN, M. J. A. (1861). "Beiträge zur praktischen Augenheilkunde", p. 163. Hoffmann and Campe, Hamburg.

WAtson, P. G., and Sevel, D. (1966). Brit. J. Ophthal., 50, 209.

\section{LASER COAGULATION}

To the Editorial Committee of the BRITISH JouRnAL OF OPHTHALMOLOGY

SIRS,-Mr. Kelly's argument (Brit. J. Ophthal., 51, 641, 1967) for the installation of laser coagulators in small clinics may be valid; but he has misquoted me. I said the laser I was using frequently produced pre-retinal haemorrhages and always destroyed the nerve-fibre layer of the retina at its higher energy settings. The scar formation accompanying these lesions was always large. I took pains to repeat that my experiments were performed on rabbits, and also to suggest that my observations should be considered by clinical ophthalmologists with this reservation in mind.

Since I presented my paper, new laser coagulators have become available and it has become apparent that when one compares one instrument with another, the size of the laser's retinal image must be considered together with the retinal energy-density. Such evidence as there is suggests that for a given energy-density the larger the image-size the more useful will be the lesion.

Yours faithfully, J. MeLlerio.

Department of Physiological Optics, INSTITUTE OF OPHTHALMOLOGY, JUdD ST., LoNDON, W.C.1. November 20, 1967. 